\title{
The ADHD teen integrative data analysis longitudinal (TIDAL) dataset: background, methodology, and aims
}

\author{
Margaret H. Sibley ${ }^{1,2^{*}}$ and Stefany J. Coxe ${ }^{3}$
}

\begin{abstract}
Background: The Attention Deficit Hyperactivity Disorder (ADHD) Teen Integrative Data Analysis Longitudinal (TIDAL) dataset integrates data from four randomized trials.

Method: Participants with ADHD ( $N=854 ; 72.5 \%$ male, 92.5\% racial/ethnic minority, ages 10-17) were assessed three times across 12 months. Data includes parent, self, and teacher ratings, observations, and school records. The battery was harmonized using an Integrative Data Analysis (IDA) approach to form variables that assign unique values to all participants.

Results: The data will be used to investigate: (1) profiles that organize the heterogeneous population into clinically meaningful subgroups, (2) whether these profiles predict treatment response, (3) heterogeneity in treatment response and variables that predict this response, (4) how treatment characteristics and adjunctive supports predict treatment response, and (5) mediators of treatment and whether these mechanisms are moderated by treatment characteristics.
\end{abstract}

Conclusions: The ADHD TIDAL Dataset will be openly shared with the field to maximize its utility.

Keywords: ADHD, Longitudinal data, Adolescence, Intervention

\section{Background}

The teenage years are a critical period for ADHD intervention. Longitudinal studies indicate a close relationship between adolescent functioning and ADHD persistence into adulthood [1-3]. Moreover, high neuroplasticity during adolescence may potentiate skill learning that maintains long-term [4], while negative adolescent life events (i.e., legal troubles, dropout, teen pregnancy) derail adult trajectories [1]. The last 10 years witnessed a proliferation of empirically-supported psychosocial interventions for

\footnotetext{
* Correspondence: margaret.sibley@seattlechildrens.org

${ }^{1}$ Department of Psychiatry and Behavioral Sciences, University of Washington School of Medicine, Seattle Children's Research Insitute, 2001 8th Ave., Suite 400, Seattle, WA 98117, USA

${ }^{2}$ Department of Psychiatry \& Behavioral Health, Florida International University, 11200 SW 8th Street, Miami, FL 33199, USA

Full list of author information is available at the end of the article
}

adolescents with ADHD [5, 6]. These interventions teach adolescents compensatory skills to mitigate the effects of executive functioning deficits on daily life while training adult stakeholders to use age-appropriate contingency management to reduce the effects of rewards processing deficits [7, 8]. Psychosocial treatments are a strong developmental-fit to the adolescent period because: (1) adolescents with ADHD often dislike stimulant medication and desist use $[9,10]$ and (2) adolescent psychosocial treatments outperform medication in mitigating ADHDrelated impairment, showing medium to large effects [6].

Despite their efficacy, implementation and utilization of adolescent ADHD treatments are poor [11-14]. Thus, efforts are needed to identify patient and service delivery barriers and facilitators. Understanding who fails to

(c) The Author(s). 2020 Open Access This article is licensed under a Creative Commons Attribution 4.0 International License, which permits use, sharing, adaptation, distribution and reproduction in any medium or format, as long as you give appropriate credit to the original author(s) and the source, provide a link to the Creative Commons licence, and indicate if changes were made. The images or other third party material in this article are included in the article's Creative Commons licence, unless indicated otherwise in a credit line to the material. If material is not included in the article's Creative Commons licence and your intended use is not permitted by statutory regulation or exceeds the permitted use, you will need to obtain permission directly from the copyright holder. To view a copy of this licence, visit http://creativecommons.org/licenses/by/4.0/ The Creative Commons Public Domain Dedication waiver (http://creativecommons.org/publicdomain/zero/1.0/) applies to the data made available in this article, unless otherwise stated in a credit line to the data. 
engage in treatment and why will signal opportunities to decrease treatment disparities.

The clinical profiles of adolescents with ADHD are highly heterogeneous [15-17]; yet, almost nothing is known about which treatments work best for whom, when, where, and how. Practitioners have few guidelines for treatment optimization-critical choices that influence a treatment credibility and patient retention in care [18]. Studies investigating questions of moderation and mediation are necessary to inform nuanced clinical care decisions [19, 20]. Unlike treatments for childhood ADHD [21], there are almost no large-scale trials of treatment for adolescent ADHD. Much could be gleaned from a large-scale investigation of mechanisms of change in adolescent ADHD treatment, identification of treatment-relevant phenotypes that influence response, and tracing the role of adjunctive supports (i.e., medication, parent involvement style, school accommodations) in enhancing or detracting from psychosocial treatment. Rich clinical information could be derived from investigating how treatment response varies as a function of person- and service delivery-level variables [22].

Pursuing these aims require person-level approaches (i.e., mixture modeling, latent class analysis) [23]. As the field of child and adolescent mental health moves toward precision medicine [24], personal-level analyses are essential to ensuring maximally effective care. Precision medicine studies have led to important advances in the treatment of childhood conduct problems [25] and adult depression [19], among other disorders. These analyses require large sample sizes that have not yet been available in the treatment of adolescent ADHD.

\section{Overview of the ADHD TIDAL dataset}

To increase data resources in the field of adolescent ADHD, we constructed the ADHD Teen Integrative Data Analysis Longitudinal (ADHD TIDAL) dataset. The ADHD TIDAL dataset will be openly shared with the field. We integrated data from four randomized trials $(N=854$; ages 10-17) [26-29] that cumulatively tested the comparative efficacy of unique five treatment conditions (i.e., evidence-based parent-teen therapy, group parent training and teen organization skills training, intensive summer treatment, usual care psychotherapy, no treatment) and included data from three unique settings (university clinic, schools, community mental health). These data were combined using an Integrative Data Analysis [30] framework, resulting in a comprehensive dataset. In the current paper, we describe the dataset, our methodology, planned analyses to pursue a linked series of personlevel research questions, and additional research questions that scientific investigators might pursue using the dataset.

\section{Construction and content Integrative data analysis}

Integrative data analysis is a relatively new technique that allows researchers to pool raw data from multiple studies to produce cumulative scientific knowledge [30]. IDA differs from more well-known techniques for combining information, such as meta-analysis, in that IDA analyzes pooled raw data from each study rather than summary statistics. IDA has several advantages over separate analysis of each study [31], including increased statistical power, management of sample heterogeneity, and increased frequency of low base-rate behaviors. IDA framework required us to: (1) code study characteristics, (2) harmonize measures and/or create commensurate measures, and (3) select a type of IDA. The four included studies vary on a variety of characteristics (i.e., treatment and comparison groups, referral source, and time of year for treatment). A major task for IDA is carefully coding each study on these characteristics. Per Hussong and colleagues [31], we coded each study based on sampling approach, history, design characteristics, and measurement. Codes are integrated into analyses as dictated by research questions.

To conduct an analysis on the combined dataset, the same variables must be present in some form in all studies. The four studies were conducted by the same investigators, so many measures of interest are common across studies (e.g., Diagnostic Interview Schedule for Children) [32] and require no additional work to use in an IDA (though IDA provides an opportunity to explore measurement invariance across studies). Other measures, such as parent depression (e.g., Patient Health Questionnaire-9,Symptom Checklist90-Revised, World Health Organization Quality of Life) [33-35] and ADHD symptoms (i.e., DSM-IV-TR vs. DSM5 symptom checklists) [6] are not identical, requiring development of commensurate measures. Commensurate measures typically involve item response theory (IRT) analysis to create common scale scores $[36,37]$.

IDA allows for either random or fixed effects models, depending on the number of studies and whether a study is conceptualized as a random sample from the population of interest. Fixed effects IDA conceives of each study as a known, specific sample from the population and can be conducted with as few as two studies. Random effects IDA conceives of each study as a random sample from the population and requires a minimum of 20 to 30 studies. The ADHD TIDAL dataset includes four studies, so all analyses are conducted within a fixed-effects IDA framework. This means that dummy codes indicating study membership are included in each analysis to account for differences between studies. We interpret all results within a fixed effects IDA framework indicating that: (1) we can only make inferences back to the specific studies, not to similar studies 
on this population and (2) we cannot fully disaggregate some between- and within-study effects, due to studyspecific code variables in analyses (i.e., whether variance attributed to "summer treatment program" is due to time of year or dose).

\section{Study designs \\ Common elements}

Our four studies were chosen for the IDA because they shared common characteristics that promoted successful harmonization. From 2010 to 2019, the research team conducted seven longitudinal treatment outcome studies of psychosocial treatment for adolescents with ADHD. We sought to include studies in the IDA that: (1) included participants from the large local school district with standardized attendance, grades, and disciplinary data, (2) possessed inclusion criteria that all participants meet DSM criteria for ADHD during a comprehensive psychiatric evaluation that included a structured parent interview (Diagnostic Interview Schedule for Children; DISC) [32] and parent and teacher symptom and impairment ratings that were integrated and reviewed by licensed clinical psychologists; (3) possessed a randomized controlled trial design; and (4) included baseline, posttreatment, and follow-up data points. Based on these criteria, two of the research teams studies were excluded from the IDA because they did not possess a follow-up data point and one was excluded because it did not possess a randomized control group. Comparison of the four included studies indicated additional common features that suit the IDA framework: (1) Autism Spectrum Disorders were exclusionary in all studies (participants with other comorbidities were included) and (2) all study participants were permitted to continue stimulant medication and special education interventions at school. These adjunctive treatments were monitored carefully and can be included as time varying covariates in analyses. An overview of study design features is provided in Table 1.

\section{Study $A$}

In study A (see Table 1) [26] middle school students were randomized to Supporting Teens' Autonomy Daily (STAND) [38] in the university clinic or a treatment as usual control group in which no treatment was offered to participants by the research team. Admission to the study used a cohort design with students receiving 10 weeks of treatment in the spring (cohort 1 and cohort 2) or the fall (cohort 3) of the academic year. At post-treatment, all participants had data from at least one source and $95 \%$ of participants had data from at least two sources. At follow-up, 97\% had data from at least one source and $87 \%$ had data from at least two sources [26].

\section{Study $B$}

Study B (see Table 1) [27] randomly assigned rising 6th or 9th graders with ADHD to the intensive Summer Treatment Program-Adolescent (STPA) or group STAND (STAND-G). School district personnel delivered the STP-A, which was held in district schools with bus transportation provided. In the fourth year of the study, a no treatment comparison group of 107 students was recruited and tracked using the same assessment schedule to contextualize group differences between the two active treatment arms. Retention converged at 90-95\% across sources, time points, and groups [27].

Table 1 Study Characteristics of the ADHD TIDAL Dataset

\begin{tabular}{|c|c|c|c|c|}
\hline & Study A & Study B & Study C & Study D \\
\hline Sample Size & $N=128$ & $N=325$ & $N=123$ & $N=278$ \\
\hline Referral source & Parent/Teacher Clinic Referral & School-Referred & $\begin{array}{l}\text { Parent/Teacher Clinic } \\
\text { Referral }\end{array}$ & Community Mental Health \\
\hline Setting & University Clinic & School & University Clinic & Community Mental Health \\
\hline Time of Year & Fall or Spring & Summer & Fall, Winter, or Spring & Fall, Winter, or Spring \\
\hline Treatment Duration & 10 weeks & 8 weeks & $8-10$ weeks & 10 weeks \\
\hline Treatment Arms & $\begin{array}{l}\text { STAND }(n=67) \\
\text { NOTX }(n=61)\end{array}$ & $\begin{array}{l}\text { STP-A }(n=109) \\
\text { STAND-G }(n=109) \\
\text { NOTX }(n=107)\end{array}$ & $\begin{array}{l}\text { STAND }(n=63) \\
\text { STAND-G }(n=60)\end{array}$ & $\begin{array}{l}\text { STAND }(n=138) \\
\text { UC }(n=140)\end{array}$ \\
\hline Clinician Type & $\begin{array}{l}\text { Graduate and Post-Graduate } \\
\text { Trainees, Masters Level }\end{array}$ & $\begin{array}{l}\text { School District Staff, College } \\
\text { Student Interns }\end{array}$ & $\begin{array}{l}\text { Graduate Trainees, } \\
\text { Licensed Clinicians }\end{array}$ & $\begin{array}{l}\text { Community Mental Health } \\
\text { Practitioners }\end{array}$ \\
\hline Start of study & Fall 2011 & Spring 2012 & Spring 2014 & Fall 2015 \\
\hline BL to POST & 6 months & 6 months & 6 months & 4 months \\
\hline $\mathrm{BL}$ to $\mathrm{FU}$ & 12 months & 12 months & 12 months & 10 months \\
\hline
\end{tabular}

Note. STAND Supporting Teens' Autonomy Daily; STAND-G STAND-Group; STP-A Summer Treatment Program-Adolescent; NOTX No treatment provided by research team; UC Usual Care in Community Mental Health. BL Baseline, POST Post-treatment; FU Follow-up 


\section{Study C}

Middle or high school students with ADHD (see Table 1; $N=123$ ) were randomly assigned to STAND or STAND$G$ using a stratified randomization procedure within study wave [28]. Study enrollment occurred in six waves with approximately ten participants per modality per wave. Recruitment occurred across 24 months with each wave occurring approximately 4 months apart. Treatment was delivered on a rolling basis throughout the academic year, with a pause in recruitment and treatment over the summer months. Retention was strong at post-treatment (95.1-97.6\%) and follow-up (85.4-91.9\%).

\section{Study $D$}

This trial (see Table 1) tested the effectiveness of STAND versus Usual Care in a sample of middle and high school students with ADHD $(N=278)$ who were incoming patients at four community mental health clinics. Over 3 years, treatment was provided by agency employees who were randomly assigned to receive STAND training and supervision or treat cases using UC practices. Adolescents were also randomized to STAND vs. UC. Retention was 99.3\% at post-treatment and $97.5 \%$ at follow-up (data from at least one informant).

\section{Heterogeneity}

Combining the data across the four studies increases sample heterogeneity and allows for examination of between-study heterogeneity. Heterogeneity (i.e., variance) is an advantage when trying to find relationships between variables. Particularly in studies of clinical populations, restricted range can reduce statistical power and impede detection of relationships between variables. The larger, more heterogeneous combined sample improves statistical power. In addition, traditionally underrepresented groups (e.g., girls with ADHD) and behaviors (e.g., conduct disorder) are well-represented in the IDA sample.

While the four studies are similar in scope, they also differ in several ways. Study B includes school-referred youth, study D includes patients in community agencies, and studies $\mathrm{A}$ and $\mathrm{C}$ included patients at a university clinic. Studies A and B utilize a no treatment control group; studies $\mathrm{B}, \mathrm{C}$, and D compare active treatments, including therapist-selected intervention in community mental health (i.e., agency usual care). Study B included summer treatment, while studies A, C, and D included treatment delivered at various points during the school year.

\section{Demographic Characteristics}

Demographic characteristics of the full sample $(N=854)$ are presented in Tables 2 and 3. The larger combined dataset allows for examination of typically low base-rate
Table 2 Demographic Characteristics of the ADHD TIDAL

Dataset $(\mathrm{N}=854)$

\begin{tabular}{|c|c|}
\hline \multicolumn{2}{|l|}{ Adolescent Demographic } \\
\hline Age $M(S D)$ & $13.33(1.58)$ \\
\hline \multicolumn{2}{|l|}{ Gender \% (n) } \\
\hline Male & 72.5 (619) \\
\hline Female & $27.5(235)$ \\
\hline \multicolumn{2}{|l|}{ Race/Ethnicity \% (n) } \\
\hline White Non-Hispanic & $7.5(64)$ \\
\hline African-American & $13.5(115)$ \\
\hline Hispanic Any Race & $77.2(659)$ \\
\hline Other & $1.8(16)$ \\
\hline Number of Siblings M (SD) & $1.80(1.39)$ \\
\hline \multicolumn{2}{|l|}{ Parent Demographic } \\
\hline \multicolumn{2}{|l|}{ Primary Caregiver \% (n) } \\
\hline Mother & $89.2(762)$ \\
\hline Father & $8.2(70)$ \\
\hline Other & $2.6(22)$ \\
\hline \multicolumn{2}{|l|}{ Parent Education Level \% (n) } \\
\hline High School or less & $21.2(181)$ \\
\hline Some college or Associate's & $29.9(255)$ \\
\hline Bachelor's degree & $31.1(266)$ \\
\hline Master's degree or higher & $17.4(149)$ \\
\hline Undisclosed & $0.7(6)$ \\
\hline Single Parent \% (n) & $39.2(334)$ \\
\hline \multicolumn{2}{|l|}{ Parent Primary Language \% (n) } \\
\hline English & $74.4(635)$ \\
\hline Spanish & $25.6(219)$ \\
\hline
\end{tabular}

sample characteristics. There are many clinicallymeaningful behaviors that are infrequently exhibited, even in clinical samples of adolescents with ADHD, such as superior IQ, predominantly hyperactive/impulsive presentation, or conduct disorder. Tables 2 and 3 illustrate that typically underrepresented patient populations, such as females and African-Americans with ADHD can be pooled across studies to create cell sizes that are now sufficient for analysis.

\section{Treatment conditions}

Supporting teens' autonomy daily (STAND)

STAND is an engagement-focused psychosocial treatment for adolescent ADHD. STAND is manualized and consists of 10 weekly 60 -min sessions attended by the adolescent and parent. Skill instruction is blended with Motivational Interviewing [39] and guided parent-teen behavioral contracting [40]. Treatment targets family, behavioral, and academic impairment. In the engagement phase, MI is used to increase awareness of 
Table 3 Clinical Characteristics of the ADHD TIDAL Dataset

\begin{tabular}{ll}
\hline Estimated Full Scale IQ M (SD) & 96.59 (13.13) \\
ADHD Diagnosis \% (n) & \\
ADHD-Predominantly Inattentive Type & $46.6(398)$ \\
ADHD-Combined Type & $53.0(453)$ \\
ADHD-Predominantly H/I & $0.4(3)$ \\
Oppositional Defiant Disorder \% (n) & $42.5(363)$ \\
Conduct Disorder \% (n) & $5.7(49)$ \\
Baseline ADHD Medication \% (n) & $35.9(307)$ \\
School Accommodations \% (n) & \\
Individualized Education Plan & $33.4(285)$ \\
Section 504 Plan & $18.5(158)$ \\
None & $45.9(392)$ \\
Unreported & $2.2(19)$ \\
Class Placement \% (n) & \\
Gifted & $17.0(145)$ \\
Regular & $68.5(585)$ \\
Regular + Special Education/Inclusion & $12.1(103)$ \\
Self-Contained Special Education & $1.8(15)$ \\
Unreported & $0.7(6)$ \\
\hline
\end{tabular}

personal values and goals, identify strengths, and recognize ways to achieve goals by acting consistently with values. The skills phase is designed to teach parentteen communication, parent behavioral strategies, and organization, time management and planning skills applied to homework, school, and chores. Planning sessions teach families to integrate skills into a daily routine, transfer new habits to school settings, and build a final parent-teen contract. In all studies, STAND was offered in either English or Spanish. Therapists are offered 3 days of training.

\section{STAND-group}

STAND-Group (STAND-G) is manualized and consists of eight 90 -min weekly sessions attended by the adolescent and parent [38]. Parents and adolescents meet in separate groups for the first $75 \mathrm{~min}$ and a blended parent-teen group for the final $15 \mathrm{~min}$. Parent training employs the community-based model [41], alternating between didactic instruction, and small and full group discussions. Parents are exposed to the same skills as in STAND, including how to monitor academics, set a daily routine, apply behavioral principles to homework, and create a parent-teen contract. The adolescent skills group alternated didactic instruction (e.g., introduction of a new skill), hands on activities (e.g., organizing one's backpack with a peer), and discussion exercises (e.g., debating the pros and cons of writing in a planner). Adolescents and parents are given suggested exercises to practice skills at home between sessions (e.g., negotiating a homework plan, organizing one's backpack and scheduling parent backpack checks). Therapists receive 1 day of training prior to implementing treatment. In study $B$, school consultation was offered in addition to STANDG; however, almost no participants received a meaningful dose of this intervention component [14].

\section{Summer treatment program-adolescent}

The 8-week STP-A [27] includes $45 \mathrm{~h}$ of youth directed treatment per week. Intervention includes rotating group modules targeting materials management, time management, planning, homework completion, note-taking, study skills, writing skills, self-monitoring, decisionmaking (including LifeSkills@ Training) [42], social pragmatics, and independently managing responsibilities in a vocational program. Contingency management is incorporated to enhance adolescent motivation to practice skills. A two-week training includes didactics, discussions, tests, role-playing, and practice. Each day, lead counselors telephone parents to provide a verbal summary of the adolescent's performance on daily treatment goals and offer coaching on home contingency management. Parents also receive an eight-week manualized parent training curriculum [43] as described for STAND-G.

\section{Usual care}

Usual Care (UC) therapists at community mental health agencies were instructed to treat study cases using usual procedures in the agency and the treatments they believed would be most effective. They received weekly supervision from agency supervisors according to typical agency practices. Complex analyses of UC practices have been proposed as a future direction; at present, UC psychotherapy for adolescent ADHD remains a black box.

\section{No treatment}

In Study A, a treatment as usual comparison group was offered no treatment by the study team. In Study B, an untreated comparison group was followed in the fourth year of the study. In these conditions, participants were permitted to pursue naturalistic treatment in their communities.

\section{Measures and available data}

Table 4 lists available data for each of the measures by administration schedule.

\section{Adolescent academic problems checklist}

The self, parent, and teacher-report versions of the 24-item Adolescent Academic Problems Checklist (AAPC) measure observable secondary-school specific organization, time management, and planning (OTP) problems and are validated for use in samples of adolescents with ADHD [44]. The AAPC possesses two distinct factors (academic skills 
Table 4 Measures Administration and Available Data in ADHD TIDAL Dataset

\begin{tabular}{|c|c|c|c|c|c|c|c|c|c|c|c|c|c|c|c|}
\hline & \multicolumn{5}{|c|}{ Baseline } & \multicolumn{5}{|c|}{ Post-Treatment } & \multicolumn{5}{|c|}{ Follow-up } \\
\hline & $A$ & B & C & $\mathrm{D}$ & N & A & B & C & $\mathrm{D}$ & $N$ & $A$ & B & C & $\mathrm{D}$ & N \\
\hline \multicolumn{16}{|l|}{ Adolescent Academic Problems Checklist } \\
\hline Self & $x$ & $x$ & - & - & 453 & $x$ & $x$ & - & - & 416 & $x$ & $x$ & - & - & 411 \\
\hline Parent & $x$ & $x$ & $x$ & $x$ & 852 & $x$ & $x$ & $x$ & $x$ & 776 & $x$ & $x$ & $x$ & $x$ & 735 \\
\hline Teacher & $x$ & $x$ & $x$ & $x$ & 844 & $x$ & $x$ & $x$ & $x$ & 798 & $x$ & $x$ & $x$ & $x$ & 759 \\
\hline \multicolumn{16}{|l|}{ Conflict Behavior Questionnaire } \\
\hline Self & $x$ & $x$ & $x$ & $x$ & 850 & $x$ & $x$ & $x$ & $x$ & 780 & $x$ & $x$ & $x$ & $x$ & 757 \\
\hline Parent & $x$ & $x$ & $x$ & $x$ & 853 & $x$ & $x$ & $x$ & $x$ & 780 & $x$ & $x$ & $x$ & $x$ & 733 \\
\hline \multicolumn{16}{|l|}{ Disruptive Behavior Disorder-Rating Scale } \\
\hline Parent & $x$ & $x$ & - & - & 452 & $x$ & $x$ & - & - & 412 & $x$ & $x$ & $x$ & - & 389 \\
\hline Teacher & $x$ & $x$ & - & - & 448 & $x$ & $x$ & - & - & 418 & $x$ & $x$ & $x$ & - & 404 \\
\hline \multicolumn{16}{|l|}{ DSM-5 ADHD Rating Scale } \\
\hline Parent & - & $x^{a}$ & $x$ & $x$ & 582 & - & $x^{a}$ & $x$ & $x$ & 503 & - & - & $x$ & $x$ & 344 \\
\hline Teacher & - & - & $x$ & $x$ & 399 & - & - & $x$ & $x$ & 381 & - & - & $x$ & $x$ & 356 \\
\hline Self & - & $x^{a}$ & - & $x$ & 292 & - & $x^{a}$ & - & - & 104 & - & $x^{a}$ & - & - & 104 \\
\hline Child Behavior Checklist & $x$ & $x$ & - & $x$ & & - & $x$ & - & $x$ & & - & $x$ & - & $x$ & \\
\hline Parent Items & & & & & 731 & & & & & 540 & & & & & 518 \\
\hline Parent T-Scores & & & & & 731 & & & & & 540 & & & & & 529 \\
\hline Youth Self Report & $x$ & $x$ & & $x$ & & - & & & $x$ & & & & - & $x$ & \\
\hline Youth Items & & & & & 730 & & & & & 544 & & & & & 549 \\
\hline Youth T-Scores & & & - & & 730 & & $x$ & - & & 547 & - & $x$ & & & 556 \\
\hline \multicolumn{16}{|l|}{ Direct Observation of Organization } \\
\hline Organization Checklist & $x$ & $x$ & - & $x$ & 702 & $x$ & $x$ & - & $x$ & 652 & $x$ & $x$ & - & $x$ & 587 \\
\hline Daily Planner Use & $x$ & $x$ & - & $x$ & 651 & $x$ & $x$ & - & $x$ & 629 & $x$ & $x$ & - & $x$ & 594 \\
\hline \multicolumn{16}{|l|}{ School Records } \\
\hline GPA & $x$ & $x$ & $x$ & $x$ & 829 & $x$ & $x$ & $x$ & $x$ & 811 & $x$ & $x$ & $x$ & $x$ & 768 \\
\hline Percentage of Work Turned In & $x$ & $x$ & $x$ & $x$ & 795 & $x$ & $x$ & $x$ & $x$ & 782 & $x$ & $x$ & $x$ & $x$ & 736 \\
\hline Average Assignment Grade & $x$ & $x$ & $x$ & $x$ & 796 & $x$ & $x$ & $x$ & $x$ & 781 & $x$ & $x$ & $x$ & $x$ & 736 \\
\hline Average Test Grade & $x$ & $x$ & $x$ & $x$ & 774 & $x$ & $x$ & $x$ & $x$ & 755 & $x$ & $x$ & $x$ & $x$ & 736 \\
\hline Disciplinary Incidents & - & $x$ & - & $x$ & 599 & - & $x$ & - & $x$ & 578 & - & $x$ & - & $x$ & 567 \\
\hline \multicolumn{16}{|l|}{ Standardized Testing } \\
\hline IQ & $x$ & $x$ & $x$ & $x$ & 854 & - & - & - & - & - & - & - & - & - & - \\
\hline Reading Achievement & $x$ & $x$ & - & $x$ & 727 & - & - & - & - & - & - & - & - & - & - \\
\hline Math Achievement & $x$ & $x$ & - & $x$ & 731 & - & - & - & - & - & - & - & - & - & - \\
\hline \multicolumn{16}{|l|}{ Impairment Rating Scale } \\
\hline Parent Academic Item & $x$ & $x$ & $x$ & - & 573 & $x$ & $x$ & $x$ & - & 521 & $x$ & $x$ & $x$ & - & 487 \\
\hline Teacher Academic Item & $x$ & $x$ & $x$ & - & 545 & $x$ & $x$ & $x$ & - & 524 & $x$ & $x$ & $x$ & - & 497 \\
\hline Parent All Items & $x$ & $x$ & - & - & 451 & $x$ & $x$ & - & - & 407 & $x$ & $x$ & - & - & 383 \\
\hline Teacher All Items & $x$ & $x$ & - & - & 432 & $x$ & $x$ & - & - & 415 & $x$ & $x$ & - & - & 391 \\
\hline Diagnostic Interview Schedule for Children (DISC) & $x$ & $x$ & $x$ & $x$ & 854 & - & - & - & - & - & - & - & - & - & - \\
\hline \multicolumn{16}{|l|}{ Parent Academic Management Scale } \\
\hline Items & $x$ & $x$ & $x$ & $x$ & 850 & $x$ & $x$ & $x$ & $x$ & 777 & $x$ & $x$ & $x$ & $x$ & 728 \\
\hline Parental Involvement: Number of Hours & - & $x^{a}$ & $x$ & $x$ & 480 & - & $x^{a}$ & $x$ & $x$ & 444 & - & $x^{a}$ & $x$ & $x$ & 435 \\
\hline Caregiver Strain Questionnaire & $x$ & $x$ & - & $x$ & 731 & $x$ & $x$ & - & $x$ & 658 & $x$ & $x$ & - & $x$ & 625 \\
\hline
\end{tabular}


Table 4 Measures Administration and Available Data in ADHD TIDAL Dataset (Continued)

\begin{tabular}{|c|c|c|c|c|c|c|c|c|c|c|c|c|c|c|c|}
\hline & \multicolumn{5}{|c|}{ Baseline } & \multicolumn{5}{|c|}{ Post-Treatment } & \multicolumn{5}{|c|}{ Follow-up } \\
\hline & $\bar{A}$ & $B$ & $C$ & $\mathrm{D}$ & $N$ & $\bar{A}$ & $B$ & $C$ & $\mathrm{D}$ & $N$ & $\bar{A}$ & $B$ & C & $\mathrm{D}$ & $N$ \\
\hline Parent ADHD Self-Report Scale & $x$ & $x$ & $x$ & - & 567 & - & $x^{a}$ & $x$ & - & 218 & - & - & $x$ & - & 100 \\
\hline \multicolumn{16}{|l|}{ Parental Psychopathology } \\
\hline Symptoms Checklist-90 Revised & $x$ & $x^{a}$ & - & - & & - & - & - & - & - & - & - & - & - & - \\
\hline Items & & & & & 234 & & & & & & & & & & \\
\hline T-Scores & & & & & 234 & & & & & & & & & & \\
\hline Patient Health Questionnaire-9 & - & - & $x$ & - & 122 & - & - & $x$ & - & 115 & - & - & $x$ & - & 100 \\
\hline World Health Organization Quality of Life & - & - & - & $x$ & 266 & - & - & - & $x$ & 251 & - & - & - & $x$ & 238 \\
\hline
\end{tabular}

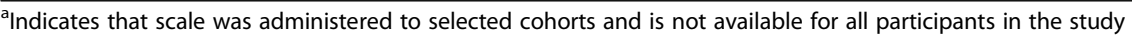

and disruptive behavior) and a total score, with strong internal reliability and concurrent validity [44]. One item was removed during scale development (locker organization) but is included.

\section{Conflict behavior questionnaire}

The parent and teen Conflict Behavior Questionnaire-20 (CBQ-20) assessed the quality of the parent-teen relationship. Respondents were asked to rate statements on a five-point scale from 1 (strongly agree) to 5 (strongly disagree) [45]. The CBQ-20 is a 20-item scale adapted from the 73-item CBQ. The CBQ-20 contains the CBQ items that best discriminated distressed and nondistressed families. It yields a single score that correlates .96 with the CBQ [45].

\section{Disruptive behavior disorders rating scale}

In the DSM-IV-TR era, the parent and teacher Disruptive Behavior Disorders Ratings Scale (DBD-RS) [46] measured Inattention (IN), Hyperactivity/Impulsivity (HI), ODD, and CD severity. Respondents were asked to rate symptoms as 0 (not at all present), 1 (just a little), 2 (pretty much), or 3 (very much). To calculate an index of symptom severity the average level $(0-3)$ of each item on the ADHD subscales is obtained. The psychometric properties of the DBD rating scale are very good, with support for internally consistent subscales [47].

\section{DSM-5 ADHD rating scale}

In the DSM-5 era, IN and HI were measured using a DSM-5 ADHD Rating Scale completed by adolescents, parents, and teachers [48]. Respondents rated symptoms of ADHD as 0 (not at all) to 3 (very much). Symptom severity is the mean level (0-3) of ADHD subscale items. Psychometric properties of the measure are very good, with empirical support for internally consistent IN and HI subscales [48]. The DSM-5 ADHD rating scale includes the adolescent/adult symptom modifiers that were introduced in the DSM-5 [49].

\section{Child behavior checklist and youth self report}

The parent-reported Child Behavior Checklist (CBCL) and Youth Self Report (YSR) were administered as broadband youth psychopathology scales [49]. These scales are well-validated measures of psychosocial adjustment problems. T-scores for the full range of clinical, diagnostic, and competence scores are included in the dataset.

\section{Observed organization skills}

Observations of planner use assessed the degree to which students recorded homework assignments. Percentage of classes in which homework was recorded (or some indication of no homework) was calculated for the last 5 days of school. Planner use was calculated as the mean of daily scores. Photocopies or screenshots were obtained to document use. If the adolescent did not record any homework, he/she received a score of zero. This measure demonstrates high inter-rater reliability (intraclass correlation was .98 in past trials) [26]. Observations of bookbag organization were obtained using an adaptation of the Organization Checklist [50]. Trained research assistants assessed dichotomously scored items on the organization checklist such as "Is the adolescent's bookbag free from loose papers?" Organization checklist scores are shown to correlate with teacher ratings of impairment in adolescents with ADHD [50].

\section{Grades}

Report cards were obtained directly from the school district at the end of each academic quarter. GPA for each quarter was calculated by converting academic grades (e.g., English, Math, Science, Social Studies) to a 5-point scale (i.e., $4.0=$ A to $0.0=$ F). Grades were not weighted for the difficulty of the class. GPA provides an objective and ecologically valid measure of school performance that is meaningful to parents and schools. The average grade on each completed assignment was also calculated. Assignments included any mandatory academic work turned in by the student except for tests, quizzes, and exams (i.e., homework, classwork, projects, presentations). Extra credit assignments and class 
participation were not counted towards this average. Missing assignments were also not weighted in the average. The average grade on each test, quiz, or exam was calculated. The percentage of assignments turned in calculated by dividing turned-in assignment count by the total number of assignments due.

\section{Disciplinary incidents}

The school district provided records of student disciplinary incidents at the end of each year. Counts of each type of disciplinary incident (e.g., detention, in-school suspension) were calculated and coded according to Robb and colleagues [51]. Minor disciplinary incidents included detentions, warnings, and being sent to an administrator or counselor due to behavioral issues. Major incidents included suspensions and expulsions.

\section{IQ and academic achievement}

The Wechsler Abbreviated Scale of Intelligence (WASI or WASI-II) was administered to participants as an index of IQ. Full-scale IQ was measured using a composite score from the Matrix Reasoning and Vocabulary subtests (Full-2) or all four subscales (Full-4) of the Wechsler Abbreviated Scale of Intelligence-2nd Edition (WASI-II) [52]. The WASI-II is a well-established test that has been validated for use with children, adolescents and adults. The WIAT-III is a standardized comprehensive academic achievement battery [53]. It has strong psychometric properties. The Numerical Operations subtest measured math achievement and the Word Reading subtest measured reading achievement. Standard scores are available for WASI and WIAT scores.

\section{Impairment rating scale}

The Impairment Rating Scale (IRS) was administered to parents and teachers (IRS) [54]. Parents and teachers indicated the adolescent's impairment severity in seven domains on a Likert scale ranging from " $0=$ no problem" to " $6=$ extreme problem." The IRS demonstrates strong psychometrics and accurately identifies ADHD-related impairment across settings and informants [54].

\section{Diagnostic interview schedule for children (DISC)}

The DISC is a structured interview that was administered to assess ADHD, ODD, and CD diagnoses. The DISC queries the presence of each symptom $(0=$ No, $1=$ Yes). The ADHD module contains supplemental probes for symptom-specific impairment [32]. Symptom presence is evaluated for each symptom of ADHD, ODD, and CD using parent reports.

\section{Parent academic management scale}

The PAMS is a 16-item checklist that measures the frequency of adaptive and maladaptive parental involvement strategies related to adolescent OTP skills [55]. Parents indicate the number of days during the typical school week (0 to 5 ) that they performed each activity. PAMS possesses strong psychometric properties as evidenced by good internal consistency, concurrent validity, and predictive validity [55]. In 2016, an item was added to the PAMS querying the number of hours the parent spends each week in activities related to the adolescent's academics.

\section{Caregiver strain questionnaire}

Parent strain stemming from the parent-adolescent relationship was measured by the 21 item Caregiver Strain Questionnaire (CSQ) [56]. The parent indicates how his/ her child's problems affected the parents and family over the past 4 weeks. Responses were scored on a 5-point scale ranging from not at all to very much a problem. The CSQ shows strong psychometric properties and the measure correlates well with other measures of family functioning.

\section{Adult ADHD self-report scale}

The Adult ADHD Self-Report Scale (ASRS) measured parental ADHD [57]. Eighteen adult-specific ADHD symptoms were rated on a five-point scale $(0=$ Never to $4=$ Very Often). The ASRS correlates highly with clinician ADHD ratings and displays strong internal consistency [57]. Parental ADHD severity is calculated as the mean score of ASRS items.

\section{Symptom Checklist-90-revised}

The Symptom Checklist-90-Revised (SCL-90-R) is a 90item broadband scale of adult psychopathology that measures nine symptom domains using a 5-point Likert scale [34]. The SCL-90-R has good internal consistency for each subscale and possesses convergent, discriminant, and predictive validity [58]. Individual items and $\mathrm{T}$ scores from the SCL-90-R are included in the dataset.

\section{Patient health Questionnaire-9}

The Patient Health Questionnaire-9 depression scale has excellent internal reliability as well as criterion and construct validity [33]. Parents reported on whether they experienced a range of depressive symptoms during the past 2 weeks, rating symptom frequency from 0 -not at all to 3-nearly every day.

\section{World Health Organization quality of life questionnaire}

Parents completed the World Health Organization (WHO) Quality of Life Questionnaire, a multidimensional profile of quality of life for cross cultural use. The English version is self-administered and covers 25 facets of quality of life within six broad domains. It captures positive and negative aspects of quality of life and possesses strong psychometric properties [35]. 


\section{Harmonization}

Harmonization of measures followed methods of Bauer (2017) [36] and Curran et al. (2008) [37].

\section{Parent depression}

Parent depression was assessed by the SCL-90 (studies A and B), PHQ-9 (study C), and the WHO QOL (study D). Specific items from the SCL-90 (13 of 90 items) and the WHO QOL (5 of 26 items) that reflected symptoms of major depression were selected; the PHQ-9 measures the nine DSM symptoms of major depression and all items were included. Each participant's item scores were combined and recoded to reflect endorsement of the nine DSM-5 major depression symptoms. Nonlinear moderated factor analysis (NLMFA) was used to determine item-specific characteristics (i.e., discrimination and difficulty) within the IRT framework, how those item characteristics vary across study, and to provide each participant with a common-scale score of depression [36]. This harmonized, common-scale score can be used in any analyses involving the total IDA sample.

\section{ADHD severity}

Adolescent ADHD symptoms were measured using DSM-IV criteria in studies A and B and using DSM-5 criteria in studies $\mathrm{C}$ and $\mathrm{D}$; both parent and teacher report of adolescent ADHD symptoms were collected. The DSM-IV-TR criteria (e.g., often fails to give close attention to details or makes careless mistakes in schoolwork, work, or during other activities) omits corresponding adolescent/adult specifiers added to the DSM-5 ADHD criteria (e.g. ... overlooks or misses details, work is inaccurate). For each participant, item scores were recoded to reflect endorsement the 18 ADHD symptoms. Since ADHD symptoms are grouped into IN and HI, a twofactor model was used. Nonlinear moderated factor analysis (NLMFA) was used to determine item-specific characteristics (i.e., discrimination and difficulty) within the IRT framework, how those item characteristics vary across study, and to provide each participant with common-scale scores of IN and HI ADHD symptoms [36]. These harmonized, common-scale scores can be used in any analyses involving the total IDA sample. Separate models and scores were created for parent report and teacher report of symptoms.

\section{Utility and discussion}

Our research team has several analyses planned using the ADHD TIDAL dataset. However, numerous opportunities for data analysis exist beyond our specific aims. We believe that pursuing personalized medicine questions for adolescents with ADHD will provide useful information that promotes improved treatment engagement and response-leading to meaningful changes in long-term outcomes. We invite additional research teams to utilize the ADHD TIDAL dataset, which is publicly available for use at the National Institute of Mental Health, National Data Archive (https://nda.nih.gov).

\section{Investigator aims}

Our first aim is to identify clinical and family-risk profiles that divide the heterogeneous population into clinically meaningful subgroups. In doing so, we will identify unobserved groups of individuals who differ from one another on a combination of baseline measures. Latent profile analysis (LPA) will be used to identify treatment-relevant phenotypes and environmental factors based on relevant individual (e.g., gender, race/ethnicity, age, ODD/CD severity, ADHD subtype, depression severity, anxiety severity, organization skills, \% of school work turned in, average test/assignment grades, school attendance, school disciplinary incidents, IQ, achievement) and family context variables (e.g., parent education level/SES, parent English skills, parent marital status, parentteen conflict, parental ADHD, parental well-being, family size). Variables that demonstrate superior psychometric properties when modeled as an observed variable will not be modeled in the context of the latent profiles.

In a second aim, we will examine whether baseline latent profile and observed variables predict treatment engagement and response. The first analyses will describe who is most at risk for treatment disengagement (i.e., medication and psychosocial). Finally, we will examine whether baseline latent profile and observed variables predict treatment response, with primary outcomes (ADHD symptoms, parent-teen conflict, and GPA) as the distal outcomes.

Our third aim will examine heterogeneity in treatment response over time. This aim will identify latent, unobserved groups of individuals who differ from one another in terms of their outcome (ADHD symptoms, parentteen conflict, GPA, OTP problems) trajectory over time. This analysis will allow us to examine this heterogeneity and determine if clinical profile, family context, adjunctive supports (e.g., medication status, parent involvement, class placement, school accommodations), and treatment characteristics (e.g., time of year, setting of treatment, \% of treatment attended, content of treatment) predict treatment response.

Our fourth aim will be to identify key treatment mediators and moderators of the relationship between treatment group and change in key outcomes (ADHD symptoms, GPA, parent-teen conflict, OTP problems). Potential mediators of the treatment effect on outcomes include teen organization skills, parent contingency management, parent-teen conflict, and parental well- 
being. Potential moderators of the treatment effect on outcomes include individual, treatment, and family variables (as noted above).

\section{Sensitivity analysis}

Given the fixed sample size, we present sensitivity analyses that provide the smallest effect that can be detected, rather than power analyses. For latent profile analyses and growth mixture models proposed in aims 1 through 3, simulation studies indicate that the Bayesian Information Criterion and bootstrap likelihood-ratio test perform best at determining the correct number of classes $[59,60]$. These studies show that these measures have at least $80 \%$ power to detect the correct number of classes when sample size is greater than 500 , if at least 8 indicators of the latent class are used. With a combined sample size of 854, we expect to have sufficient power to correctly identify emergent latent classes based on baseline variables. In aim 4 we will examine questions of moderated mediation with a sample size of 854 . For moderation analyses, treatment level variables, the individual level moderator, and their interaction will predict change over time in the outcome variable. A simplified power analysis for a repeated-measures ANOVA design with an interaction between group and time (a much less powerful model than a latent growth model) suggests that for $N=854,9$ treatment groups (across all four studies), and 3 measurement occasions, the required effect size is approximately $\mathrm{d}=0.12$, a very small effect. In previous analyses of individual studies included in this IDA, we found effect sizes of $d=0.5$ or higher for moderation of the treatment effect on ADHD symptoms (i.e., Sibley et al., 2016). For the mediation analyses, we used the tables generated by Fritz and MacKinnon [61]. With a sample size of $N=854$ and using the preferred method of bootstrap confidence intervals, we have greater than $80 \%$ power to detect even small effects for both the treatment to mediator and mediator to outcome slope. In previous analyses of individual studies included in this IDA, we found effect sizes of $d=0.5$ or higher for the moderating effect of treatment on ADHD symptoms (equivalent to the effect of a mediating variable on the outcome slope).

\section{Additional research directions}

The ADHD TIDAL dataset is suitable for examining treatment outcome questions that expand on those noted above by selecting independent and dependent variables, moderators, and mediators that our team did not incorporate into our planned analyses. Given the broad age range of participants, cross-sequential analyses with the ADHD TIDAL dataset could reveal important information about the nature of ADHD symptoms and related impairments. The samples demographic diversity also may support research questions related to gender, cultural, or socioeconomic differences in the expression of ADHD. The broad range of data available in the ADHD TIDAL dataset also may help research teams estimate effect sizes for power analyses and conduct pilot analyses prior to data collection studies, as well as further integration with existing datasets.

\section{Abbreviations \\ ADHD: Attention deficit/hyperactivity disorder; IDA: Integrative data analysis;"; GPA: Grade point average; TIDAL: Teen integrative data analysis longitudinal; DISC: Diagnostic interview schedule for children; STAND: Supporting teens' autonomy daily; STP-A: Summer treatment program-adolescent; STAND- G: Supporting teen's autonomy daily-group; UC: Usual care; \\ AAPC: Adolescent academic problems checklist; OTP: Organization, time management, and planning; CBQ: Conflict behavior questionnaire; DBD- RS: Disruptive behavior disorder rating scale; IN: Inattention; HI: Hyperactivity/ impulsivity; DSM: Diagnostic and statistical manual; CBCL: Child behavior checklist; YSR: Youth self report; WASI: Wechsler abbreviated scale of intelligence; IQ: Intelligence quotient; WIAT: Wechsler Individual achievement test; IRS: Impairment rating scale; PAMS: Parent academic management scale; CSQ: Caregiver strain questionnaire; ASRS: Adult ADHD self report scale; SCL- 90-R: Symptoms checklist-90-revised; PHQ-9: Patient health questionnaire-9; WHO: World health organization; QOL: Quality of life; NLMFA: Nonlinear moderated factor analysis; ODD: Oppositional defiant disorder; CD: Conduct disorder}

\section{Acknowledgements}

The authors acknowledge Dr. Patrick Curran for his advisement with respect to the harmonization of research data. The authors also acknowledge Ms. Mercedes Ortiz for her assistance organizing study data.

\section{Authors' contributions}

MHS pooled data, built the initial dataset, and contributed to design of the study aims noted here in. SJC conducted data coding and statistical analyses related to harmonization of the dataset. MHS and SJC contributed to paper writing. All authors have read and approved this manuscript.

\section{Funding}

This research was funded by the National Institute of Mental Health R03 MH116397. It was also supported by IES R324A120169, R01 MH106587, R34 MH092466, and the Klingenstein Third Generation Foundation Fellowship in ADHD. The funding agencies played no role in the design, administration or interpretation of research data for this study.

\section{Availability of data and materials}

The datasets generated during and/or analysed during the current study are available in the National Institute of Mental Health, National Data Archive repository, https://nda.nih.gov.

\section{Ethics approval and consent to participate}

All procedures performed in studies involving human participants were in accordance with the ethical standards of the institutional research committee (Florida International University, Social and Behavioral Institutional Review Board; IRB00008169; Reference \#: IRB-18-0415) and with the 1964 Helsinki declaration and its later amendments or comparable ethical standards. Written informed consent was obtained from all individual participants included in the study. Written parental consent and written youth assent was obtained for all participants under the age of 18 .

\section{Consent for publication}

Not applicable.

\section{Competing interests}

MHS receives book royalties from Guilford Press for a treatment manual described herein. SJC reports no conflicts of interest. 


\section{Author details}

'Department of Psychiatry and Behavioral Sciences, University of Washington School of Medicine, Seattle Children's Research Insitute, 2001 8th Ave., Suite 400, Seattle, WA 98117, USA. ²Department of Psychiatry \& Behavioral Health, Florida International University, 11200 SW 8th Street, Miami, FL 33199, USA. ${ }^{3}$ Department of Psychology, Florida International University, 11200 SW 8th Street, Miami, FL 33199, USA.

\section{Received: 2 March 2020 Accepted: 12 June 2020}

Published online: 08 July 2020

\section{References}

1. Barkley RA, Murphy KR, Fischer M. ADHD in adults: what the science says. New York: Guilford. 2008. https://doi.org/10.1177/1087054709333321.

2. Molina BS, Pelham Jr WE, Cheong J, Marshal MP, Gnagy EM, Curran PJ. Childhood ADHD and growth in adolescent alcohol use: the roles of functional impairments, ADHD symptom persistence, and parental knowledge. J Abnorm Psychol 2012;121(4):922. https://doi.org/10.1037/ a0028260.

3. Sibley MH, Pelham Jr WE, Molina BS, Coxe S, Kipp H, Gnagy EM, Meinzer M, Ross JM, Lahey BB. The role of early childhood ADHD and subsequent CD in the initiation and escalation of adolescent cigarette, alcohol, and marijuana use. J Abnorm Psychol 2014;123(2):362. https://doi.org/10.1037/ a0036585.

4. Blakemore SJ, Choudhury S. Development of the adolescent brain: implications for executive function and social cognition. J Child Psychol Psychiatry. 2006;47 https://doi.org/10.1111/j.1469-7610.2006.01611.x.

5. Chan E, Fogler JM, Hammerness PG. Treatment of attention-deficit/ hyperactivity disorder in adolescents: a systematic review. Jama. 2016; 315(18):1997-2008. https://doi.org/10.1001/jama.2016.5453.

6. Sibley MH, Kuriyan AB, Evans SW, Waxmonsky JG, Smith BH. Pharmacological and psychosocial treatments for adolescents with ADHD: an updated systematic review of the literature. Clin Psychol Rev 2014;34(3): 218-232. https://doi.org/10.1016/j.cpr.2014.02.001.

7. Castellanos FX, Sonuga-Barke EJ, Milham MP, Tannock R. Characterizing cognition in ADHD: beyond executive dysfunction. Trends Cogn Sci 2006; 10(3):117-123. https://doi.org/10.1016/j.tics.2006.01.011.

8. Sonuga-Barke EJ. Causal models of attention-deficit/hyperactivity disorder: from common simple deficits to multiple developmental pathways. Biol Psychiatry 2005;57(11):1231-1238. https://doi.org/10.1016/j.biopsych.2004.09. 008.

9. Brinkman WB, Simon JO, Epstein JN. Reasons why children and adolescents with attention-deficit/hyperactivity disorder stop and restart taking medicine. Acad Pediatr 2018;18(3):273-280. https://doi.org/10.1016/j.acap. 2017.09.005

10. Molina BS, Hinshaw SP, Swanson JM, Arnold LE, Vitiello B, Jensen PS, Epstein JN, Hoza B, Hechtman L, Abikoff HB, Elliott GR. The MTA at 8 years: prospective follow-up of children treated for combined-type ADHD in a multisite study. J Am Acad Child Adolesc Psychiatry 2009;48(5):484-500. https://doi.org/10.1097/CHI.0b013e31819c23d0.

11. Barkley RA, Edwards G, Laneri M, Fletcher K, Metevia L. The efficacy of problem-solving communication training alone, behavior management training alone, and their combination for parent-adolescent conflict in teenagers with ADHD and ODD. J Consult Clin Psychol 2001;69(6):926. https://doi.org/10.1037/0022-006X.69.6.926.

12. Bussing R, Zima BT, Mason DM, Porter PC, Garvan CW. Receiving treatment for attention-deficit hyperactivity disorder: do the perspectives of adolescents matter?. J Adolesc Health 2011;49(1):7-14. https://doi.org/10. 1016/j.jadohealth.2010.08.014

13. Evans SW, Serpell ZN, Schultz BK, Pastor DA. Cumulative benefits of secondary school-based treatment of students with attention deficit hyperactivity disorder. Sch Psychol Rev 2007;36(2):256-273. https://doi.org/ 10.1080/02796015.2007.12087943.

14. Sibley MH, Olson S, Morley C, Campez M, Pelham Jr WE. A school consultation intervention for adolescents with ADHD: barriers and implementation strategies. Child Adolesc Mental Health 2016;21(4):183-191. https://doi.org/10.1111/camh.12159.

15. Fair DA, Bathula D, Nikolas MA, Nigg JT. Distinct neuropsychological subgroups in typically developing youth inform heterogeneity in children with ADHD. Proc Natl Acad Sci 2012;109(17):6769-6774. https://doi.org/10. 1073/pnas.1115365109.
16. Martel MM, Roberts B, Gremillion M, Von Eye A, Nigg JT. External validation of bifactor model of ADHD: explaining heterogeneity in psychiatric comorbidity, cognitive control, and personality trait profiles within DSM-IV ADHD. J Abnorm Child Psychol 2011;39(8):1111. https://doi.org/10.1007/ s10802-011-9538-y.

17. Wåhlstedt C, Thorell LB, Bohlin G. Heterogeneity in ADHD: neuropsychological pathways, comorbidity and symptom domains. J Abnorm Child Psychol 2009; 37(4):551-564. https://doi.org/10.1007/s10802-008-9286-9.

18. Gray JM. The shift to personalised and population medicine. Lancet 2013; 382(9888):200-201. https://doi.org/10.1016/S0140-6736(13)61590-1.

19. Frank E, Cassano GB, Rucci P, Thompson WK, Kraemer HC, Fagiolini A, Magg L, Kupfer DJ, Shear MK, Houck PR, Calugi S. Predictors and moderators of time to remission of major depression with interpersonal psychotherapy and SSRI pharmacotherapy. Psychol Med 2011;41(1):151-162. https://doi. org/10.1017/S0033291710000553.

20. Langberg JM, Evans SW, Schultz BK, Becker SP, Altaye M, Girio-Herrera E. Trajectories and predictors of response to the challenging horizons program for adolescents with ADHD. Behav Ther 2016;47(3):339-354. https://doi.org/10.1016/j.beth.2016.01.001.

21. The MTA Cooperative Group. A 14-month randomized clinical trial of treatment strategies for attention-deficit/hyperactivity disorder. Arch Gen Psychiatry 1999;56(12):1073-1086. https://doi.org/10.1001/archpsyc.56.12. 1073.

22. Wallace ML, Frank E, Kraemer HC. A novel approach for developing and interpreting treatment moderator profiles in randomized clinical trials. JAMA Psychiatry 2013;70(11):1241-1247. https://doi.org/10.1001/jamapsychiatry. 2013.1960.

23. Collins LM, Lanza ST. Latent class and latent transition analysis: with applications in the social, behavioral, and health sciences. New York: Wiley; 2010. https://doi.org/10.1002/9780470567333.

24. Kazdin AE. Evidence-based psychosocial treatment: advances, surprises, and needed shifts in foci. Cogn Behav Pract 2016;23(4):426-430. https://doi.org/ 10.1016/j.cbpra.2015.11.003.

25. Pelham WE, Dishion TJ, Tein JY, Shaw DS, Wilson MN. What doesn't work for whom? Exploring heterogeneity in responsiveness to the family check-up in early childhood using a mixture model approach. Prev Sci 2017;18(8):911922. https://doi.org/10.1007/s11121-017-0805-1.

26. Sibley $\mathrm{MH}$, Graziano $\mathrm{PA}$, Kuriyan $\mathrm{AB}$, Coxe $\mathrm{S}$, Pelham WE, Rodriguez $\mathrm{L}$, Sanchez F, Derefinko K, Helseth S, Ward A. Parent-teen behavior therapy+ motivational interviewing for adolescents with ADHD. J Consult Clin Psychol 2016;84(8):699. https://doi.org/10.1037/ccp0000106.

27. Sibley MH, Coxe SJ, Campez M, Morley C, Olson S, Hidalgo-Gato N, Gnagy E, Greiner A, Coles EK, Page T, Pelham WE. High versus low intensity summer treatment for ADHD delivered at secondary school transitions. J Clin Child Adolesc Psychol 2018;47(2):248-265. https://doi.org/10.1080/15374416.2018. 1426005.

28. Sibley, MH, Rodriguez, LM, Coxe, SJ, Page, T, \& Espinal, K. Parent-teen group versus dyadic treatment for adolescent ADHD: what works for whom? J Clin Child Adolesc Psychol. 2019: https://doi.org/10.1080/15374416.2019.1585257.

29. Sibley, MH, Graziano, PA, Bickman, L, Coxe, SJ, Martin, P, Rodriguez, LM, Fallah, $\mathrm{N}$, Ortiz, $\mathrm{M}$ (in press). Implementing parent-teen motivational interviewing + behavior therapy for ADHD in community mental health. Prev Sci.

30. Curran PJ, Hussong AM. Integrative data analysis: the simultaneous analysis of multiple data sets. Psychol Methods 2009;14(2):81. https://doi.org/10. 1037/a0015914

31. Hussong AM, Curran PJ, Bauer DJ. Integrative data analysis in clinical psychology research. Annu Rev Clin Psychol 2013;9:61-89. https://doi.org/ 10.1146/annurev-clinpsy-050212-185522.

32. Shaffer D, Fisher P, Lucas CP, Dulcan MK, Schwab-Stone ME. NIMH diagnostic interview schedule for children version IV (NIMH DISC-IV): description, differences from previous versions, and reliability of some common diagnoses. J Am Acad Child Adolesc Psychiatry 2000;39(1):28-38. https://doi.org/10.1097/00004583-200001000-00014.

33. Kroenke K, Spitzer RL, Williams JB. The PHQ-9: validity of a brief depression severity measure. J Gen Intern Med. 2001;16(9):606. https://doi.org/10.1046/j. 1525-1497.2001.016009606.x

34. Derogatis LR. SCL-90-R: symptom Checklist-90-R: administration, scoring, and procedures manual. New York: NCS Pearson; 1996.

35. Whoqol Group. The world health organization quality of life assessment (WHOOOL): position paper from the world health organization. Soc Sci Med 1995;41(10):1403-1409. https://doi.org/10.1016/0277-9536(95)00112-K. 
36. Bauer DJ. A more general model for testing measurement invariance and differential item.functioning. Psychol Methods. 2017;22(3):507. https://doi. org/10.1037/met0000077.

37. Curran PJ, Hussong AM, Cai L, Huang W, Chassin L, Sher KJ, Zucker RA Pooling data from multiple longitudinal studies: the role of item response theory in integrative data analysis. Dev Psychol 2008:44(2):365. https://doi. org/10.1037/0012-1649.44.2.365.

38. Sibley MH. Parent-teen therapy for executive function deficits and ADHD: building skills and motivation. New york: Guilford Publications; 2016.

39. Miller WR, Rollnick S. Motivational interviewing: helping people change. New york: Guilford press; 2013.

40. Patterson GR, Forgatch M. Parents and adolescents living together: part 1: the basics. Eugene, OR: Castalia; 1987.

41. Cunningham CE. Large group, community based, family-centered parent training. Attention deficit hyperactivity disorder: A clinical workbook 2005: 480-98. https://doi.org/10.1016/j.ambp.2006.05.003.

42. Botvin GJ, Griffin KW. Life skills training: empirical findings and future directions. J Prim Prev 2004;25(2):211-232. https://doi.org/10.1023/B:JOPP. $0000042391.58573 .5 \mathrm{~b}$

43. Sibley MH, Altszuler AR, Ross JM, Sanchez F, Pelham Jr WE, Gnagy EM. A parent-teen collaborative treatment model for academically impaired high school students with ADHD. Cogn Behav Pract 2014;21(1):32-42. https://doi. org/10.1016/j.cbpra.2013.06.003

44. Sibley MH, Altszuler AR, Morrow AS, Merrill BM. Mapping the academic problem behaviors of adolescents with ADHD. Sch Psychol Q 2014;29(4): 422. https://doi.org/10.1037/spq0000071.

45. Robin AL, Foster SL. Negotiating parent-adolescent conflict: A behavioralfamily systems approach;1989.

46. Pelham Jr WE, Gnagy EM, Greenslade KE, Milich R. Teacher ratings of DSMIII-R symptoms for the disruptive behavior disorders. J Am Acad Child Adolesc Psychiatry 1992;31(2):210-218. https://doi.org/10.1097/00004583199203000-00006

47. Evans SW, Brady CE, Harrison JR, Bunford N, Kern L, State T, Andrews C. Measuring $\mathrm{ADHD}$ and ODD symptoms and impairment using high school teachers' ratings. J Clin Child Adolesc Psychol 2013;42(2):197-207. https:// doi.org/10.1080/15374416.2012.738456.

48. Sibley MH, Kuriyan AB. DSM-5 changes enhance parent identification of symptoms in adolescents with ADHD. Psychiatry Res 2016;242:180-185. https://doi.org/10.1016/j.psychres.2016.05.036.

49. Achenbach TM. The Achenbach system of empirically based assessment (ASEBA): development, findings, theory, and applications. Burlington: University of Vermont, Research Center for Children, Youth, \& Families; 2009. https://doi.org/10.1002/9781118625392.wbecp150.

50. Evans SW, Schultz BK, White LC, Brady C, Sibley MH, Van Eck K. A schoolbased organization intervention for young adolescents with attentiondeficit/hyperactivity disorder. Sch Ment Heal 2009;1(2):78-88. https://doi.org/ 10.1007/s12310-009-9009-6.

51. Robb JA, Sibley MH, Pelham WE, Foster EM, Molina BS, Gnagy EM, Kuriyan $A B$. The estimated annual cost of ADHD to the US education system. Sch Ment Heal 2011;3(3):169-177. https://doi.org/10.1007/s12310-011-9057-6.

52. Wechsler D. WASI-II: Wechsler abbreviated scale of intelligence. San Antonio: PsychCorp; 2011.

53. Wechsler D. Manual for the Wechsler individual achievement test-(WIAT-III). San Antonio; 2009

54. Fabiano GA, Pelham, Jr WE, Waschbusch DA, Gnagy EM, Lahey BB, Chronis AM, Onyango AN, Kipp H, Lopez-Williams A, Burrows-MacLean L. A practical measure of impairment: psychometric properties of the impairment rating scale in samples of children with attention deficit hyperactivity disorder and two school-based samples. J Clin Child Adolesc Psychol 2006;35(3):369-385. https://doi.org/10.1207/s15374424jccp3503_3.

55. Sibley MH, Campez M, Perez A, Morrow AS, Merrill BM, Altszuler AR, Coxe S, Yeguez CE. Parent management of organization, time management, and planning deficits among adolescents with ADHD. J Psychopathol Behav Assess 2016;38(2):216-228. https://doi.org/10.1007/s10862-015-9515-9.

56. Brannan AM, Heflinger CA, Bickman L. The caregiver strain questionnaire: measuring the impact on the family of living with a child with serious emotional disturbance. J Emot Behav Disord 1997 ;5(4):212-222. https://doi. org/10.1177/106342669700500404.

57. Adler LA, Spencer T, Faraone SV, Kessler RC, Howes MJ, Biederman J, Secnik K. Validity of pilot adult ADHD self-report scale (ASRS) to rate adult ADHD symptoms. Ann Clin Psychiatry 2006;18(3):145-148. https://doi.org/10.1080/ 10401230600801077

58. Derogatis LR, Cleary PA. Confirmation of the dimensional structure of the SCL-90: a study in construct validation. J Clin Psychol 1977;33(4):981-989. https://doi.org/10.1002/1097-4679(197710)33:4<981::AID-JCLP2270330412>3. $0 . \mathrm{CO} ; 2-0$.

59. Nylund KL, Asparouhov T, Muthén BO. Deciding on the number of classes in latent class analysis and growth mixture modeling: a Monte Carlo simulation study. Struct Equ Model. 2007;14(4):535-69.

60. Tein JY, Coxe S, Cham H. Statistical power to detect the correct number of classes in latent profile analysis. Struct Equ Model Multidiscip J. 2013;20(4): 640-57.

61. Fritz MS, MacKinnon DP. Required sample size to detect the mediated effect. Psychol Sci. 2007;18(3):233-9.

\section{Publisher's Note}

Springer Nature remains neutral with regard to jurisdictional claims in published maps and institutional affiliations.
Ready to submit your research? Choose BMC and benefit from:

- fast, convenient online submission

- thorough peer review by experienced researchers in your field

- rapid publication on acceptance

- support for research data, including large and complex data types

- gold Open Access which fosters wider collaboration and increased citations

- maximum visibility for your research: over $100 \mathrm{M}$ website views per year

At BMC, research is always in progress.

Learn more biomedcentral.com/submissions 